\title{
An Analysis of Social Seed Network and Its Contribution to On-Farm Conservation of Crop Genetic Diversity in Nepal
}

\author{
Diwakar Poudel, ${ }^{1,2}$ Bhuwon Sthapit, ${ }^{3}$ and Pratap Shrestha ${ }^{2,4}$ \\ ${ }^{1}$ Norwegian School of Economics, Department of Business and Management Science, 5045 Bergen, Norway \\ ${ }^{2}$ Local Initiatives for Biodiversity, Research and Development (LI-BIRD), P.O. Box 324, Pokhara, Nepal \\ ${ }^{3}$ Bioversity International, Office of Nepal, 93.4 Dharahara Marg, Fulbari, Ward No. 011, Pokhara, Nepal \\ ${ }^{4}$ USC Canada, 56 Sparks Street, Suite 705, Ottawa, ON, Canada K1P $5 B 1$
}

Correspondence should be addressed to Diwakar Poudel; diwakar.poudel@nhh.no

Received 28 October 2014; Accepted 2 February 2015

Academic Editor: Alexandre Sebbenn

Copyright (c) 2015 Diwakar Poudel et al. This is an open access article distributed under the Creative Commons Attribution License, which permits unrestricted use, distribution, and reproduction in any medium, provided the original work is properly cited.

\begin{abstract}
Social seed systems are important for the maintenance of crop genetic diversity on farm. This is governed by local and informal system in the community through a farmers' network. This paper analyses these local seed systems through application of social network analysis tools and mappings and examines the network member and its stability over space and time in a small rice farming community in Nepal. NetDraw software is used for data analysis and network mapping. We found that the dynamic network structure had key role in provisioning of traditional varieties and maintaining of crop genetic diversity on farm. We identify and ascertain the key network members, constituted either as nodal or bridging (connector) farmers, occupying central position in the network who promote seed flow of local crop diversity, thus strengthening crop genetic resource diversity on farm.
\end{abstract}

\section{Introduction}

A network in a social system refers to the interpersonal relationship of a set of persons connected together through flow of information, goods, or implementation of joint activities or other social bonds of one kind or another. Social network analysis is the mapping and measuring of relationships and flows of goods and information between and among people, groups, organizations, or other information/knowledge processing entities. The nodes in the network are the people and groups while the links show relationships or flows between the nodes. The network analysis provides both a visual and a mathematical analysis of human relationships [1]. Farmers' social seed network analysis is the mapping and measuring of relationships and flows of seeds between farmers. The nodes in the network are farmers while the links show relationships or flows of seeds between the farmers. Farmers' seed networks are one of the major components of farmers' informal seed system through which seed and other genetic materials flow among the farming community members [2-4]. Within these networks, certain members in the community appear to play a major role in managing the process of genetic flow and crop diversity [5]. It has been widely reported that seed requirements in most farming communities are fulfilled through informal seed supply systems [6] and on-farm management of crop genetic resources. Farmer networks have been found to be playing significant role in the flow of information and genetic materials in the Nepalese hill farming communities $[5,7]$. Literatures on the study of informal flow of seed materials through farmer's networks have shown that these networks are most important in fulfilling the genetic material needs, maintaining genetic diversity on farm $[5,8,9]$ and creating social relationship between the farmers. On-farm management of crop genetic diversity has traditionally allowed farmers to cope with adversity. The goal of on-farm management is to encourage farmers to continue to select and manage local crop populations. While the majority of farmers in developing world depend on farmsaved seed as their primary seed source, they exchange, borrow, and purchase seeds from neighbours, relatives, and 
market places. Many farmers receive seeds as a gift from their relatives and neighbours. Tripp [3] reported that information about varieties often moves through pathways of kinship and friendship. Hoang et al. [10] also reported from work in Vietnam that social networks are the most valuable asset of the resource-poor farmers which can be used to their advantage as extension and development workers can successfully communicate with the target community.

However, which member has the greater role in the network and how the social seed network is functioning are some of the issues to be understood in greater detail. This study analyses the farmers' seed system using social network analysis tools and maps to depict both the mathematical and visual relationship among the members of such networks in the community that maintains the genetic diversity using the straightforward application of known measure centrality theory.

Furthermore, a social network could also be dynamic, changing over time due to various factors that influence the social structure of a community. For any effective intervention it is important to assess how stable the social networks and the members/farmers are over time. What would be the possible implications of the social network for on-farm conservation of crop genetic diversity? This paper, therefore, aims to investigate whether the social seed networks and key members are stable over the years and examines the role of the social seed networks and the farmers in provision of local level seed supply across the members of all categories in the community. Dynamics of these networks over time in the community is also studied to assess the value of such networks to on-farm conservation and other developmental interventions.

\section{Analytical Tool: Centrality Theory}

Social network analysis is well known and widely used in many other fields while its application in analysis of farmers' seed system is relatively new. Social network theory explains a number of ways to analyze the network data. In the context of this study, classical centrality theory is applied to analyze the farmers' seed network. Although the social network theory is new in the field, there are some studies that apply the techniques to understand the farmers network (e.g., Abay et al. [9] and Thomas et al. [11]). Different centrality measures such as degree, betweenness, and closeness centrality were computed to locate the position of the farmers in the social network and to explain the flow of genetic materials among the network members in the community.

These centrality measures can be illustrated and framed in their natural historical context, that of social networks. A social network is here represented as a nonvalued graph $G$, consisting of a set of $N$ nodes (or farmers) and a set of $K$ edges or lines (the seed flows) connecting pairs of farmers. The nodes of the graph are the individuals, the farmers of a community, and the lines represent the social ties. The graph is described by the so-called adjacency matrix, a $N \times N$ matrix whose entry $a_{i j}$ is 1 if there is an edge between farmers $i$ and $j$ and 0 otherwise. The entries on the diagonal, values of $a_{i i}$, are undefined and for convenience are set equal to 0 .
2.1. Degree Centrality. Degree centrality is based on the idea that important nodes are those with the largest number of ties to other nodes in the graph. Degree centrality measures the number of direct connectedness of an individual farmer with other farmers in the network, which can be denoted as

$$
C_{D}\left(n_{i}\right)=d\left(n_{i}\right)=\sum x_{g-1},
$$

where $C_{D}\left(n_{i}\right)$ is the degree centrality and $d\left(n_{i}\right)$ is the number of farmers connected to it and $\sum x_{g-1}$ is sum of all other farmers in connection. The degree centrality could retain the value zero, no connection to the maximum connection $(g-1)$, when connected to all the farmers in the community. Consequently a standardization of this measure could be done using

$$
C_{D}^{\prime}\left(n_{i}\right)=\frac{d\left(n_{i}\right)}{(g-1)}
$$

which is independent of $g$ (the members in the network) and thus can be compared across networks of different sizes. This is visible and must be easy to compute and understand. Higher degree centrality means many direct connections with other network members [12].

2.2. Betweenness Centrality. Betweenness centrality measures relationship of a farmer with the other members in terms of the position he/she occupies to control what flows in the network. This also explains the interaction between the two farmers that are not connected directly but indirectly through the third individuals/farmers. Let $C_{B}\left(n_{i}\right)$ be betweenness centrality, $g_{j k}$ the number of connection between farmer $j$ and $k$, and $g_{j k}\left(n_{i}\right) / g_{j k}$ the estimated probability that this path be chosen. Then the betweenness centrality index for farmers $n_{i}$ is given as sum of these estimated probabilities over all pair of farmers excluding $i$ th farmer,

$$
C_{B}\left(n_{i}\right)=\sum_{j<k} \frac{g_{j k}\left(n_{i}\right)}{g_{j k}} .
$$

It has a minimum of zero to its maximum of $(g-1)(g-$ $2) / 2$, which is the number of pairs of farmers not including $n_{i}$. Higher betweenness centrality means higher indirect connections and greater influence in the network. These farmers (nodes) play important role in connecting the other members by connecting the subnetwork in the community, also called node cuts or cut points $[12,13]$.

\subsection{Flow Betweenness Centrality. The betweenness centrality} measure characterizes farmers as having positional advantage, or power, to the extent that they fall on the shortest (geodesic) pathway between other pairs of farmers. However, there are several extensions for cases in which communication does not travel through geodesic paths only [14-16]. In particular, the flow betweenness is defined by assuming that each edge of the graph is like a pipe and can carry a unitary amount of flow [14]. By considering a generic node 
TABLE 1: Characteristics of the study sites and community.

\begin{tabular}{lccc}
\hline Characteristics & & Study sites & \\
& Begnas, Kaski & Kholako Chhew, Kaski & Kachorwa, Bara \\
\hline Altitude m asl & $800-1206$ & $600-800$ & $80-100$ \\
Physiographic region & Mid hill & Low hill & Tarai $^{\dagger}$ \\
Community size & 941 & 400 & 914 \\
Ethnic composition & Brahmin, Chhetri, Gurung, & Brahmin, Chhetri, Gurung, & Brahmin, Yadav, Teli, Tatma, \\
& Newar, Gharti, Hill Dalit & Newar, Gharti, Giri, Hill Dalit & Sunar, Malah, Harijan, \\
Market accessibility & Low & Low to Medium & Medium to high \\
Farming system & Subsistence & Subsistence & Subsistence to commercial \\
Landrace diversity & High & High & Medium \\
Modern var. diversity & Low & Medium & High
\end{tabular}

${ }^{\dagger}$ Tarai is defined as Indo-gangatic plains across Indo-Nepal boarder in southern part of Nepal.

$j$ as the source of flow and a generic node $k$ as the target, it is possible to calculate the maximum possible flow from $j$ to $k$ by means of the min-cut, max-flow theorem [17]. Suppose that there are two farmers who want to have a relationship but the geodesic path between them is blocked by reluctant farmers and if there exists another pathway, the two farmers are likely to use it, even if it is longer and "less efficient." In general, farmers may use all of the pathways connecting them, rather than just geodesic paths. The flow approach to centrality expands the notion of betweenness centrality. It assumes that farmers will use all pathways that connect them, proportionally to the length of the pathways. The flow betweenness centrality of node $i$ is defined as

$$
C_{i}^{F}=\frac{\sum m_{j k}(i)}{\sum m_{j k}}
$$

where $m_{j k}(i)$ is the amount of flow passing through $i$ when the maximum flow $m_{j k}$ is exchanged from $j$ to $k$.

\section{Study Sites}

The study was carried out in three villages of Nepal, Begnas and Kholako Chhew in Kaski district and Kachorwa in Bara district. Agriculture is the major occupation for most people in all of the study communities. The majority of the households also have multiple sources of income that includes the nonfarm employment, remittances, and wage laboring in all the ecosites. Rice is the major staple crop and is grown in different environments including irrigated land, partially irrigated land, and rain fed land, both lowlands and uplands. These study communities are characterized by different socioeconomics and demographic diversity. They represent a wide range of physiographic regions, situated at different altitudes, have many ethnic compositions, have low to high access to markets, and represent subsistence to commercial farming systems and have high crop genetic diversity. The specific characteristics of the study communities and villages are given in Table 1.

\section{Data Collection, Analysis, and Mapping}

4.1. Data Collection. The study employed the chronological data collection at three different points of time. The study was conducted on rice seed supply system as the diversity at the household and community level is higher than other crops [18]. Data were collected in 2001, 2003, and 2005 with an interval of two growing seasons. The study had employed a sociometric survey using the snowball-sampling technique to collect the network data [5]. In this technique there is an initial sample of respondents as "starters" from whom data on their network links are collected. The sociometrically indicated individuals in the first round of starters then become the second stage respondents. These second stage respondents consequently lead to the third stage respondents and so on. Thus the snowball sampling follows a multistage design in which respondents at each stage sociometrically determine who the respondents will be at the following stage [13, 19-21].

During the study in 2001, the initial "starter" sample of 24 respondents was drawn on the basis of stratified random sampling of three socioeconomic strata from the list of a baseline household study [22, 23] and consequently followed the sociometric names in the second and third stage as the respondents identified in each stage thereafter as a receiver or giver of seed. In year 2003 and 2005 studies, the same 24 initial starter respondents of the 2001 survey were taken as the first-round starters. The respondents, thereafter, were taken from the sociometrically identified individuals in each stage of interviews. The survey was carried out until the third stage. The reason of taking the same 24 respondents in the second and third time is to enter in the same network of the initial year and assess the stability of the farmers' network and nodal farmers over time. The nodal farmers were identified by using the criteria such as frequency of mentions of their names/the number of links in the network.

The respondents were asked to provide the names of the farmers from whom they had obtained the seeds or to whom they had given the seeds during the "last two growing 
TABLE 2: Identification of the key members in the social seed network who occupy central position in the social network as a nodal or bridging farmer by estimating different centrality scores.

\begin{tabular}{|c|c|c|c|c|}
\hline \multirow{2}{*}{ Farmer (node) $^{\mathrm{a}}$} & \multicolumn{3}{|c|}{ Estimated centrality scores ${ }^{\mathrm{b}}$} & \multirow{2}{*}{ Position in the network ${ }^{c}$} \\
\hline & Degree centrality & Betweenness centrality & Flow-betweenness centrality & \\
\hline 07 & $7(6.731)$ & $48(0.448)$ & & NB \\
\hline 14 & $4(3.846)$ & & & $\mathrm{N}$ \\
\hline 16 & $4(3.846)$ & $35(0.327)$ & $5(0.047)$ & NBA \\
\hline 17 & $5(4.808)$ & $33(0.308)$ & $6(0.056)$ & NBA \\
\hline 20 & $4(3.846)$ & $14(0.131)$ & & NB \\
\hline 21 & $5(4.808)$ & $10(0.093)$ & & NB \\
\hline 22 & & $12(0.112)$ & $3(0.028)$ & BA \\
\hline 24 & & $15(0.140)$ & $3(0.028)$ & BA \\
\hline 31 & $4(3.846)$ & & & $\mathrm{N}$ \\
\hline 34 & $4(3.846)$ & $06(0.056)$ & & NB \\
\hline 36 & $6(5.769)$ & $10(0.093)$ & $4(0.037)$ & NBA \\
\hline 37 & $4(3.846)$ & $25(0.233)$ & $13(0.121)$ & NBA \\
\hline 38 & $5(4.808)$ & $27(0.252)$ & $12(0.112)$ & NBA \\
\hline 40 & $4(3.846)$ & & $9(0.084)$ & NA \\
\hline 41 & $4(3.846)$ & $5(0.047)$ & $2(0.019)$ & NBA \\
\hline 43 & $4(3.846)$ & & $2(0.019)$ & NA \\
\hline 44 & $6(5.769)$ & $18(0.168)$ & $9(0.084)$ & NBA \\
\hline 45 & & $20(0.187)$ & $19(0.177)$ & $\mathrm{BA}$ \\
\hline
\end{tabular}

${ }^{\mathrm{a}}$ Number " 07 " means the code for the household $07,{ }^{\mathrm{b}}$ the figures in the parentheses are normalized score, ${ }^{\mathrm{c}} \mathrm{N}$ denotes nodal farmer, $\mathrm{B}$ denotes bridging farmer creating an optimal path, and A denotes bridging farmer creating alternate paths in the network.

seasons" in each study. This was verified through the next stage survey. Stability of the network and its members were then examined and measured by comparing the data of 2001, 2003, and 2005. The data set also contained socioeconomic and demographic information of farmers, name of varieties/landraces in transaction, and means of transaction or flow of seed.

4.2. Data Analysis and Mapping. For the first part of the analysis of the network, we used UCINET [24] and Netdraw [25] to analyze the centrality measures and mapping. Data were entered in the MS Excel sheet, coded, and then transferred in the VNA format. While coding the data, "farmers" were considered as node data, their characteristics were considered as node properties, and "means of flow" of seeds among farmers and "the varieties" in transaction were the tie data. These VNA data were then analysed using NetDraw (version 2.41), which is simple software that can be used for data analysis and network mapping. The different means of flow of seeds and the varieties were coded to generate the numerical values in this analysis. The relationship of the nodes/farmers within the network was compared through the analysis of the degree, betweenness, and flow betweenness centrality. Network maps were generated by using the centrality values to add clarity in the visual analysis of the social seed networks.

For the second part of the analysis, basically we employed descriptive statistics but also used SPSS (Statistical Package for Social Sciences) for $\chi^{2}$ analysis to examine the accessibility of seeds to different categories of the farmers in the community.

\section{Results and Discussions}

The results of social seed network or farmers' seed network are presented in two subsections. The first subsection defines, discusses, and characterizes the farmers' network and its members in the network based on the centrality theory presented in Section 2. In the second subsection, we analyze the stability of the networks and the members over space and time. The stability of the networks and the members over three different study sites and three different points of time has been compared and discussed. Finally, the implication of the networks and their stability on the conservation of crop genetic diversity is discussed and analyzed.

5.1. Characterizing the Farmers' Network and Its Members. The centrality score has been computed to show that different kinds of farmers can be found in the social network. These farmers can be identified as nodal farmer or connector farmer as defined earlier. Network maps and tables are generated to identify the members of the network that are nodal or the key farmers in the community. Furthermore, the network mapping reveals that there are large numbers of local varieties/landrace of rice which flow among farmers in the community thus maintaining the agrobiodiversity. Figure 1(a) shows the degree centrality and Figure 1(b) shows the betweenness centrality of the farmers in Begnas village, one of the study sites. Both degree centrality and betweenness centrality scores are presented to rank the farmers in the network (Table 2). Based on the given visual maps and mathematical scores, we distinguish and define the farmers either 


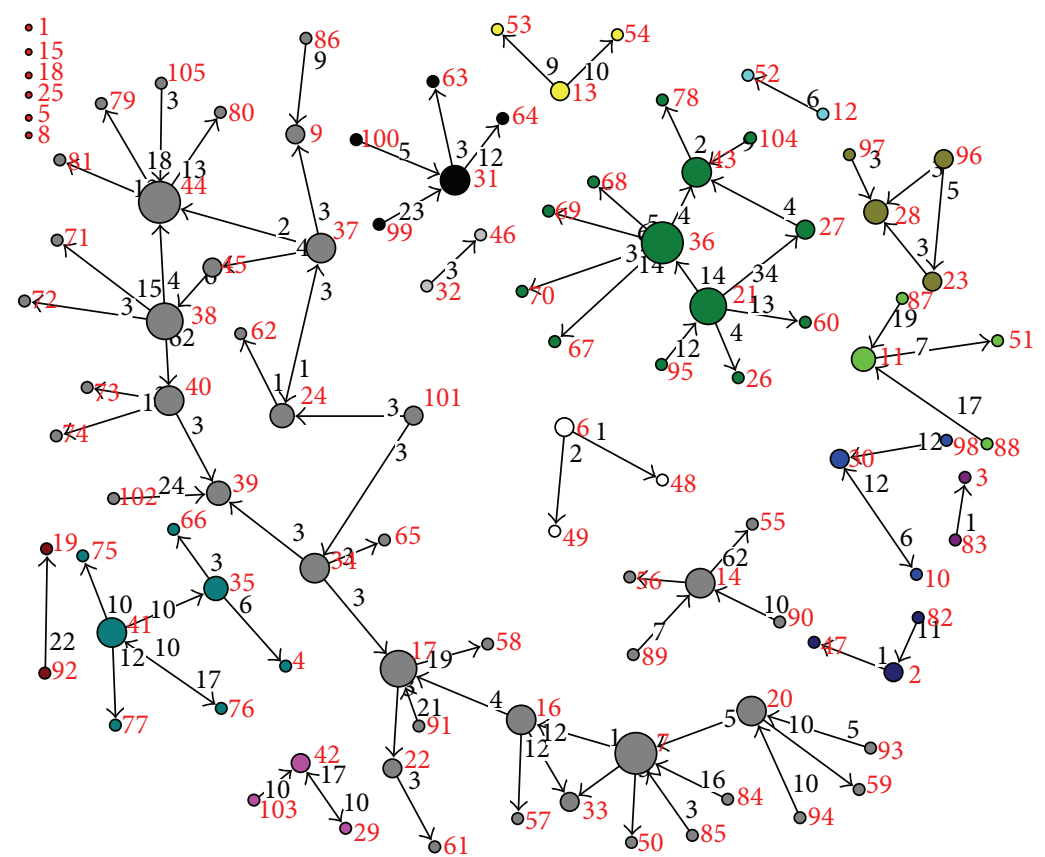

(a)

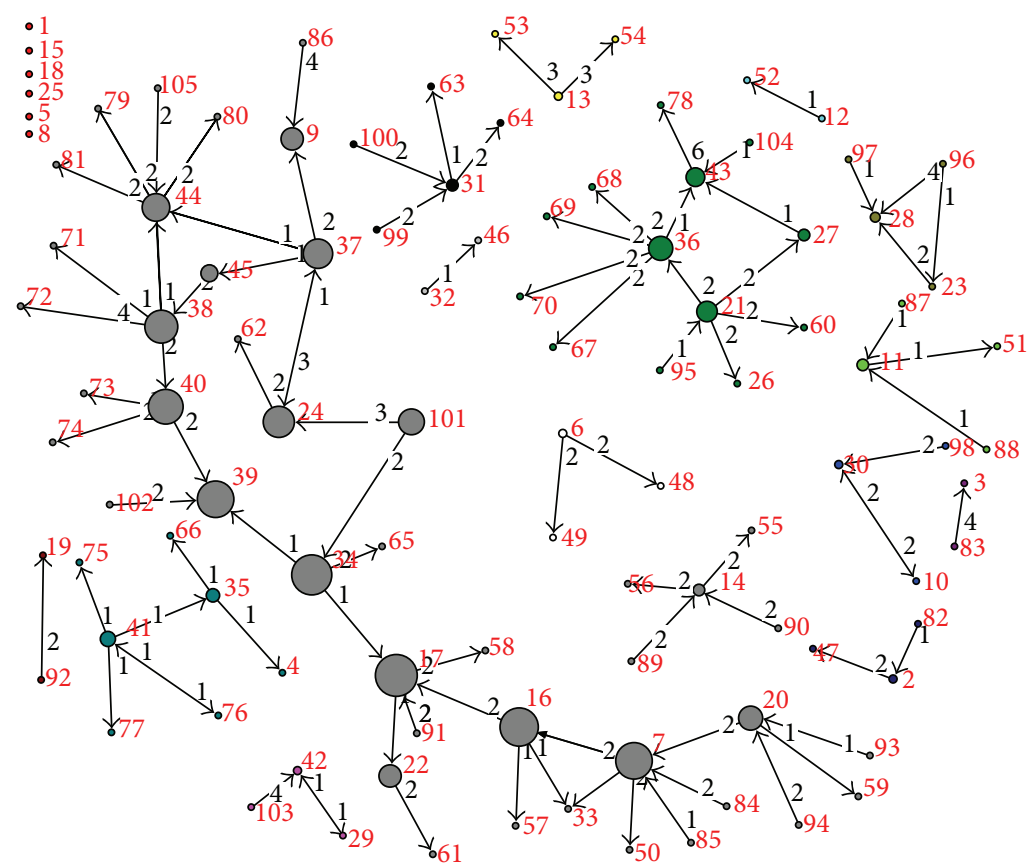

(b)

FIGURE 1: Farmers' social seed networks showing large networks, small networks, and subnetworks in Begnas study village. Node size is an indication for the degree centrality or the betweenness centrality of the household; arrows indicate the direction of the seed flow; node color differentiates the networks; the red numbers indicate code for the households; black numbers indicate the code for variety and code for flow of the variety: (a) the degree centrality of farmers and varieties and (b) betweenness centrality and mode of flow of the varieties $(1.0=$ exchange, $2.0=$ gift, $3.0=$ purchase, and $4.0=$ loan). The individual numbers are the isolates or isolated farmers in the network.

as a nodal farmer or connector farmer and the network as large networks or small networks that can play prominent role in the informal seed systems and maintenance of agricultural biodiversity on farm in the community.
5.1.1. Nodal Farmers. The findings based on the degree centrality measures reveal that 15 farmers out of 105 responding farmers in the community possess direct link with 4 or more members in the network. A farmer in the network having 
high degree centrality or more number of direct connections or link is considered as nodal farmer, although no explicit criteria are available for such classification. The major farmers having high degree centrality in the network are presented in Table 2. These individuals in the seed network play significant role in the flow of genetic materials and information in the community and occupy relatively more central position (node) in the network [5].

5.1.2. Connector or Bridging Farmers. Betweenness centrality measures the property of the farmers as a connector among their network and subnetworks who can also be called cut point farmers $[13,21]$. Farmers having high betweenness centrality score occupy the central position in the social seed network. These farmers play important role in connecting the other members or subnetwork. Such farmers are found to be very important for flow of seeds or genetic materials within and between networks/subnetworks. They may not be connected to many members directly in the network like nodal farmers but are playing connector role by connecting two or more subnetworks, thus maintaining long chain for seed system. The major individuals occupying the central positions in the study are given in Table 2 . These farmers could be dangerous and could be point of failure for the social network if they leave farming, migrate to other place, or die.

Based on these centrality measures (Table 2), the farmers occupying the key position in the network are identified as farmers $07,14,16,17,20,21,22,24,31,34,36,37,38,40,41$, 43,44 , and 45 . These farmers are either nodal plus bridging farmers, or nodal, or bridging farmers in the network. For example, it can be observed that farmer " 07 " is one of the very important farmers who has both the highest links with many farmers in the community directly (degree centrality) and can create the shortest or the optimal path for the flow of materials within the community (betweenness centrality). Furthermore, there are some farmers who can create alternate path in the network to reach the farmers that are less accessible through the shortest paths. These farmers can be identified by measuring the flow betweenness centrality in the network. For example farmer " 45 " can create the alternate paths to connect the farmers that are otherwise not connected in the network, although these paths are not optimal or efficient but useful in the flow of seed materials. By estimating the different centrality measures, we can identify farmers in the community that occupy the key positions in the network for distribution of seeds and information within and among subnetworks in the community.

5.1.3. Characteristics of the Nodal or Bridging Farmers. The study also aimed to find out the characteristics of nodal farmers in the community to examine the possibility of involving them in maintenance of crop genetic diversity and developmental interventions and extension. The study found that the nodal and bridging farmers represent every ethnic group and gender and socioeconomic strata. Although more nodal farmers were from upper class "Brahmin/Chhetri" and "Magar/Gurung" ethnics than from Dalits/Sudra and Muslims, this difference was statistically not significant
$(P>0.05)$. The nodal farmers were both men and women with no statistically significant gender bias (Table 3 ).

The majority of the nodal farmers belong to the rich socioeconomic strata followed by the medium strata farmers and then by the poor farmers $(P<0.01)$. The farmers with higher education are also more likely to be nodal farmers than illiterate farmers $(P<0.01)$. Table 3 also shows that farmers who have off-farm employments along with farming tend to be nodal farmers as compared to the full time farmers $(P<0.05)$. In summary, both men and women can be nodal or bridging farmers. These farmers are richer, better educated, and more mobile than other farmers in the network as they have a range of social connection and wider access to information. These farmers are apparently responsible for bringing genetic material and associated knowledge into the village.

5.1.4. The Network Mapping. While network mapping could be created using different variables showing particular characteristics of networks such as sex of the members, ethnicity of the members, resource endowment of members, and locality, in the study, only a few important variables are shown. These variables in the network maps include connector or nodal farmers, their position in the network, means of seed/varieties flow, flow direction, and type of crop varieties in transaction and the subnetworks. Larger node size indicates that these farmers are nodal or bridging farmers in the community. They have higher number of direct or indirect connections with other farmers and occupy key position in the network.

These networks maps show that there are several networks in the community that could be small and large. A large seed network refers to farmers with many farmers in the links, and small network refers to few farmers connected to the links, whereas a subnetwork relates to many smaller networks in the larger network. These networks and subnetworks are created as a function of social relationships or social interdependence in the community. In the given maps, we can also see that there are some farmers who are not connected to the networks, which are referred to as isolates. These isolated farmers indicate that there is further scope to include them in the seed network. From the given network maps, we can easily figure out who provides the seeds, who receives it, how the flow occurs, and which seeds are being transacted in the community (e.g., from Figures 1(a) and 1(b), it can be observed that farmer 34 provides $(\rightarrow)$ seed type 3 to farmer 65 as a gift (2.0)).

5.1.5. Flow of Genetic Materials. Figure 1(b) shows that exchange, gift, purchase, and loan are the current social practices of informal flow of genetic materials in three communities of Nepal. Seeds are acquired either in the form of exchange (changing seeds for seeds of different varieties), bartering (with grains or other crops), gifts (receiving free of cost), or purchasing (in the form of cash payment) that occur in the farmers' network. The major means of seed flow were found to be the exchange and gift. Only small quantity was traded as sell/purchase and loan system (Table 4). Over 
TABLE 3: Characteristics of the nodal or bridging farmers in Begnas, Kholako Chhew and Kachorwa study sites.

\begin{tabular}{|c|c|c|c|c|}
\hline \multirow{2}{*}{ Characteristics } & \multirow{2}{*}{ Level } & \multicolumn{2}{|c|}{ Nodal farmers $n=87$} & \multirow{2}{*}{$\chi^{2}$ significance $(P$ value $)$} \\
\hline & & No. & $\%$ & \\
\hline \multirow{4}{*}{ Ethnicity } & Brahmin/Chhetri & 47 & 18 & \multirow{4}{*}{0.105} \\
\hline & Magar/Gurung/Vaisya & 33 & 15 & \\
\hline & Dalits & 5 & 7 & \\
\hline & Muslims & 2 & 7 & \\
\hline \multirow{2}{*}{ Sex of respondents } & Male & 57 & 16 & \multirow{2}{*}{0.393} \\
\hline & Female & 30 & 13 & \\
\hline \multirow{3}{*}{ Occupation } & Agriculture & 76 & 14 & \multirow{3}{*}{0.013} \\
\hline & Nonagriculture & 0 & 0 & \\
\hline & Both & 9 & $33^{* *}$ & \\
\hline \multirow{3}{*}{ Socioeconomic status } & Rich & 44 & 19 & \multirow{3}{*}{0.004} \\
\hline & Medium & 33 & 17 & \\
\hline & Poor & 10 & $7^{* * *}$ & \\
\hline \multirow{3}{*}{ Age of respondents } & Below 30 years & 13 & 17 & \multirow{3}{*}{0.196} \\
\hline & $30-60$ years & 65 & 16 & \\
\hline & Above 60 years & 9 & 9 & \\
\hline \multirow{4}{*}{ Education } & Illiterate & 16 & 8 & \multirow{4}{*}{0.000} \\
\hline & Literate/primary & 31 & 14 & \\
\hline & Secondary & 22 & 24 & \\
\hline & College/university & 8 & $29^{* * *}$ & \\
\hline
\end{tabular}

TABLE 4: Means (modes) of informal seed flow of rice through farmers' networks.

\begin{tabular}{|c|c|c|c|c|c|c|c|c|c|}
\hline \multirow{3}{*}{ Means of flow } & \multicolumn{9}{|c|}{ Percent (\%) flow of genetic materials in different sites and time } \\
\hline & \multicolumn{3}{|c|}{ Begnas (mid hill) } & \multicolumn{3}{|c|}{ Kholako Chhew (low hill) } & \multicolumn{3}{|c|}{ Kachorwa (Tarai plains) } \\
\hline & 2001 & 2003 & 2005 & 2001 & 2003 & 2005 & 2001 & 2003 & 2005 \\
\hline Exchange & 53 & 64 & 51 & 58 & 54 & 67 & 64 & 56 & 52 \\
\hline Gift & 31 & 30 & 42 & 36 & 38 & 30 & 17 & 5 & 6 \\
\hline Purchase & 16 & 6 & 7 & 6 & 8 & 3 & 19 & 39 & 42 \\
\hline
\end{tabular}

the period of five years, seed exchange is the most common practice of seed flow within the community followed by receiving the gifts and purchasing the preferred seed.

The term "seed exchange" is often used to describe local level seed supply driven by local demand. Farmers exchange seed of one type with other types with each gaining a new variety and benefiting from the exchange. Farmers also exchange seed of one crop with seed of another crop as a bartering system. The ratio of bartering of rice seed was $1: 1$ or $1: 1.5$ or different, depending up on (a) other variety seeds, (b) other crop seeds, (c) grain, and (d) other crop grains.

The gift system is still a predominant system in Begnas (30 to $42 \%$ ) and Kholako Chhew (30 to $38 \%$ ) study villages of hill environment whereas in case of Kachorwa, the trend of providing seed as gift, in general, is declining and the trend on purchasing has been increasing. Although seed exchange remains the major mechanism of the seed flow, there is a variation in the degree of seed flow through exchange when compared over time (Table 4).
5.2. Stability Analysis. The study also aimed to find out the key farmers stability over the years. This will help to examine the possibility of involving nodal farmers as maintenance of crop genetic diversity and developmental interventions such as scaling out of products of participatory plant breeding through farmer to farmer extension. In this section, we analyze and discuss the stability of key members (nodal farmers) and their seed networks over space and time. The network members' stability refers to their existence in the network over the period of time and space. Similarly network stability is a degree to which similar network links occur at two or more points of time and space [8]. In this study, we have analyzed the data in three different points of time (2001, 2003, and 2005) and three different study sites.

5.2.1. Nodal Farmers Stability. An analysis of the "stability in number of nodal farmers" and the "stability of nodal farmers" in the farmers' network over the study period shows that the total number of nodal farmers decreased significantly 
TABLE 5: Stability in number of nodal farmers in rice seed networks across study sites.

\begin{tabular}{|c|c|c|c|}
\hline \multirow{2}{*}{ Study sites } & \multicolumn{3}{|c|}{ Number of nodal farmers in different points of time } \\
\hline & 2001 & 2003 & 2005 \\
\hline Begnas (mid hill) & $18(21 \%)^{\dagger}$ & $5(08 \%)$ & $9(19 \%)$ \\
\hline Kholako Chhew (low hill) & $8(16 \%)$ & $7(23 \%)$ & $7(21 \%)$ \\
\hline Kachorwa (Tarai plains) & $26(34 \%)$ & $10(12 \%)$ & $2(2 \%)$ \\
\hline
\end{tabular}

TABLE 6: Stability of initial nodal farmers in rice seed networks across study sites.

\begin{tabular}{|c|c|c|c|}
\hline \multirow{2}{*}{ Study sites } & \multicolumn{3}{|c|}{ Stable nodal farmers over different points in time } \\
\hline & 2001 & 2003 & 2005 \\
\hline Begnas (mid hill) & 18 & $5(27)^{\dagger}$ & $1(5)^{\dagger}$ \\
\hline Kholako Chhew (low hill) & 8 & $4(50)$ & $2(12)$ \\
\hline Kachorwa (Tarai plain) & 26 & $7(27)$ & $0(0)$ \\
\hline
\end{tabular}

${ }^{\dagger}$ Figures in parentheses refer to the percent of stable nodal farmers from 2001.

in Kachorwa from 2001 to 2005 ( $P<0.01)$. However, it has remained the same in the Begnas and Kholako Chhew ecosites except at Begnas in 2003. At Begnas, the nodal farmers decreased due to natural calamities (occurrence of hailstone) affecting the crop in 2005. In general, it can be seen that proportion of nodal farmers are stable in hill farming systems but they are very dynamic in the Tarai farming systems (Table 5).

Although the proportion of the nodal farmers in Begnas and Kholako Chhew study villages have remained almost the same overtime (during the 5 years period), most of the nodal farmers identified in the latter surveys in the same communities were new members. Only about 5 percent nodal farmers in Begnas and 12 percent in nodal farmers in Kholako Chhew are the same individuals who have remained as nodal farmers over the study period (Table 6). These farmers are considered the stable nodal farmers in the seed flow networks.

The stability of individual nodal farmers in rice seed networks is poor in Tarai village (2\%) and not very high in hill agroecosystems (19 to 21\%) during 5-year period. The current trend of decline in the number of nodal farmers in Tarai study site is due to the increased awareness about the importance of on-farm conservation of local varieties [26]. In addition, the establishment of the community seed bank (CSB) in the village has fulfilled the seed needs of the people [26, 27]. On the contrary, the other two sites in hill agroecosystems the number of nodal farmers did not change very much because they remain the primary source of seeds in the absence of a community seed bank or better access to the market.

On the other hand, while comparing the network members over the study period in the different sites, we found that network members change over the time. It is found that $44 \%$ to $62 \%(n=23-52)$ of the initial network members were the same in the three villages studied over the two points of time (2001 cf. 2003). However, by 2005 only $21 \%$ to $47 \%$ of the members $(n=17-37)$ remained the same (Table 7$)$.
TABLE 7: Stability in network members in rice seed networks across study sites over time.

\begin{tabular}{|c|c|c|}
\hline \multirow[t]{2}{*}{ Sites/years } & \multicolumn{2}{|c|}{$\begin{array}{l}\text { Stability in network members over } \\
\text { time within the community }\end{array}$} \\
\hline & $2003^{\dagger}$ & $2005^{\delta}$ \\
\hline Begnas (mid hill) & $52(62 \%)$ & $18(21 \%)$ \\
\hline Kholako Chhew (low hill) & $23(44 \%)$ & $17(33 \%)$ \\
\hline Kachorwa (Tarai plains) & $44(56 \%)$ & $37(47 \%)$ \\
\hline
\end{tabular}

${ }^{\dagger}$ Figures in the parenthesis mean the percentage of the member with respect to 2001 members.

${ }^{\delta}$ Figures in the parenthesis means the percentage of the member with respect to 2001 and 2003 members.

New members joined the network to acquire seed after a natural calamity in Begnas, while the easy access of markets as source of seed of new varieties led to opportunities for new contacts to obtain seeds in Kachorwa. In Begnas, most of the network members changed as the network broke down and reestablished due to the hailstorm of 2003. Change in network members in Kholako Chhew and Kachorwa was lower compared to Begans. Some of the reasons of change of network members are due to natural calamities, change in generation, new varietal choice, seed saving by the farmers themselves, establishment of community seed (CSB), and increased market access. This study reveals that the seed networks were found to be dynamic and change over time and space as members come and go or change their roles from nodal to nonnodal farmers.

5.2.2. Networks Stability. While analyzing the farmers' networks, we found that there were two very large networks with 12 subnetworks links in 2001 in Begnas (Table 8). These farmers' networks broke down into one large network with 4 subnetworks and 10 smaller networks in 2003. In 2005, there were two large networks with 12 subnetworks in the same 
TABLE 8: Stability of social seed networks and subnetworks at different study sites over time.

\begin{tabular}{|c|c|c|c|c|c|c|}
\hline \multirow{3}{*}{ Study sites } & \multicolumn{6}{|c|}{ Number of strong and weak networks in the community over time } \\
\hline & \multicolumn{2}{|c|}{2001} & \multicolumn{2}{|c|}{2003} & \multicolumn{2}{|c|}{2005} \\
\hline & Large networks ${ }^{\dagger}$ & Small networks & Large networks & Small networks & Large networks & Small networks \\
\hline Begnas (mid hill) & $2(12)$ & 0 & $1(4)$ & 10 & $2(12)$ & 6 \\
\hline Kholako Chhew (low hill) & $\mathrm{n} / \mathrm{a}$ & - & $1(7)$ & 4 & $1(6)$ & 6 \\
\hline Kachorwa (Tarai plains) & $1(15)$ & 8 & - & - & $1(6)$ & 9 \\
\hline
\end{tabular}

${ }^{\dagger}$ Figures in the parenthesis denote the number of subnetworks within the networks.

study site (Begnas). Similarly in Kachorwa, we found one large network with 15 subnetworks and 8 smaller networks in 2001. By the year 2005, this number was changed to one large network with 6 subnetworks and 9 smaller networks. In Kholako Chhew site, we found one large network with 7 subnetworks and 4 smaller networks in 2003. The study in 2005 also shows that the network is dominated by a single large network with 6 subnetworks and 6 smaller networks in the community. Although the size of subnetworks reduced by a half in Tarai site (Kochorwa), it remained the same in the hilly study regions. The data shows that large network remains the same whereas the number of subnetworks and small networks varied over the studied period.

The breakdown of large seed networks of Begnas into smaller network in 2003 was due to heavy hailstorm during the crop maturing stage that reduced total crop production and seed availability for planting the next season. Therefore, farmers did not have enough seeds to exchange within their network as they did in 2001 and consequently size of subnetworks reduced as the numbers of small networks increased. However, in 2005, the larger networks resumed along with some smaller networks thus increasing the social seed network in the community. It is true that stochastic events like hailstorm affect informal seed supply system negatively but unpredictability of such events motivate communities for maintenance of portfolio of varieties and social seed exchange system. It is therefore assumed that social seed network can provide a buffer for local crop diversity at the time of climatic adversity.

Similarly in Kachorwa village, the larger seed network of 2001 was broken down to many smaller networks in the community because of the increased access to market links, change in perception of farmers regarding seed saving (as the farmers started to save own seed), and establishment of community seed bank (CSB) (CSB is a community-driven agrobiodiversity approach to conserve local varieties with the objectives of sharing information and easy access of local crop diversity [26].) that is helpful in supplying seeds and genetic materials to the members in the community (also reported in Shrestha et al. [26]). However, in Kholako Chhew, the farmers' seed network was more stable over the study period showing that the social seed networks are stable over time in communities facilitating provision of local seed requirement.

Generally informal flow of seed/planting materials does not have to occur among all the members of the community. There would be flows of materials through a number of spatially distributed smaller networks. In a larger social network, direct contact with all the individuals may not be possible while the subnetworks are enough in the diffusion of seed genetic materials and information and they are linked to other subnetworks when need arise. Data shows that the network members were more stable than the individual nodal farmers and therefore significance of large network with many subnetworks for on-farm conservation should be recognized.

\section{Discussion and Conclusion}

6.1. Farmers' Network as a Vehicle for Flow of Genetic Materials. Farmer-to-farmer seed exchange is a common social practice to share genetic materials because it is a reliable and trustworthy mechanism to access seed and information. The findings agree with work of Badstue et al. [4] and Louette [28]. They are mostly based on social networks and family relations and can be very efficient and effective in the diffusion of modern or local varieties $[2,29]$. The most common way of managing seed is by exchanging seeds for seeds or grain and gifts within or outside the community. This informal seed supply system in the community plays important role to fulfill the seed requirement and also improves the conservation of the crop genetic resources on farm. Farmers acquire seed using variety of networks of social relations and different types of seed transactions. They seek seeds to replace poor quality seeds, to grow better cultivars they saw in another farmer's field, to test new cultivars, to look for suitable cultivars to replace the existing one for specific land parcel, and to fight disease or pest infestation. The majority of seed flow occurs within a community as gifts, exchange and bartering within the context of social custom. However, the traditional social seed systems are showing changes in practice of more seed purchase rather than providing seed lots as a gift at least in Tarai region where seed markets are more active. Although the informal seed systems are recognized as the cheapest and the most reliable source of seed and information [30], its importance in terms of low cost and reliable access of local germplasm cannot be guaranteed.

The majority of farmers keep their own seed for both modern and local varieties [31]. But occasionally they have to obtain seed from their social network members due to stochastic events such as drought, hailstorm, flood, frost, and excessive rain leading to crop failure and loss of seed for the next season. Most farmers interviewed valued farmerto-farmer exchange process since the social seed networks help to ensure seed availability and thereby maintain genetic 
TABLE 9: Percent of farmers acquiring rice seeds from nodal farmers over time.

\begin{tabular}{lcccc}
\hline \multirow{2}{*}{ Farmers } & & Farmers acquiring seed in different years (\%) & Total & $P$ value \\
\hline Acquiring seeds & 2001 & 2003 & 2005 & 52 \\
Not acquiring seeds & 58 & 52 & 47 & 53 \\
\hline
\end{tabular}

TABLE 10: Characteristics of the farmers acquiring rice seed in the community.

\begin{tabular}{|c|c|c|c|}
\hline Farmers characteristics & Level & Farmers acquiring seed & $\chi^{2}$ significance $(P$ value $)$ \\
\hline \multirow{3}{*}{ Socioeconomic status } & Rich & $77\left(41^{\dagger}\right)$ & \multirow{3}{*}{0.000} \\
\hline & Medium & $98(59)$ & \\
\hline & Poor & $93(59)$ & \\
\hline \multirow{4}{*}{ Ethnicity } & Brahmin/Chhetri & $107(50)$ & \multirow{4}{*}{0.674} \\
\hline & Magar/Gurung & $101(54)$ & \\
\hline & Dalits (KDS) & $38(55)$ & \\
\hline & Muslim & $12(44)$ & \\
\hline \multirow{2}{*}{ Sex of respondents } & Male & $160(53)$ & \multirow{2}{*}{0.566} \\
\hline & Female & $98(51)$ & \\
\hline \multirow{3}{*}{ Occupation } & Agriculture & $236(52)$ & \multirow{3}{*}{0.451} \\
\hline & Nonagriculture & $11(42)$ & \\
\hline & Both & $11(61)$ & \\
\hline \multirow{4}{*}{ Education } & Illiterate & $93(51)$ & \multirow{4}{*}{0.090} \\
\hline & Literate/primary & $96(52)$ & \\
\hline & Secondary & $61(60)$ & \\
\hline & College/university & $6(30)$ & \\
\hline \multirow{3}{*}{ Age of respondents } & Below 30 years & $31(49)$ & \multirow{3}{*}{0.078} \\
\hline & $30-60$ years & $189(55)$ & \\
\hline & Above 60 years & $38(42)$ & \\
\hline
\end{tabular}

${ }^{\dagger}$ Figures in parentheses represent percentages with respect to the total number in the category.

integrity of landrace population. But the study was not designed to test that hypothesis. Despite extinction of farmlevel population of a crop due to stochastic events, we found that there are enough thriving varieties in other farmers' fields that provide seed for the next season and thus maintain the genetic diversity in the larger landscape. Alvarez et al. [32] reported that the local seed supply system functions like a source-sink metapopulation because of this feature of individual farm populations providing seed source to other farm populations that have gone extinct. This is an interesting area of future research as rice farming of these communities suffers from climatic variability.

The colonization (can be measured by the number of households growing a particular variety within the community and also area under each variety at the household or community levels.) of the farmer-preferred population occurs in the seed system when farmers adopt the new seed population through exchange, gifts, purchase, or similar means. The larger and stable network might function as a source of threatened landrace thus conserving the local crop genetic resource, whereas the smaller and dynamic network provides an opportunity of evolutionary and human selection through migration (such as exchange and gift). This traditional informal social system in fact allows farmers and communities to maintain a portfolio of local crop diversity, which in turn allows farmers to develop adaptive strategies to cope with the effect of climate change at the local scale. Very limited research has been done in this context as well.

6.2. Farmers' Network as a Source of Seed Acquisition. Underlying purpose of social seed networks is to improve farmers' access to wide range of genetic resources and associated information. The farmers' network is found to be useful in supplying seeds and genetic material to all the farmers of the different social and economic groups in the community. Table 9 shows that the proportion of farmers acquiring seeds and information over time from nodal farmers has not been changing significantly $(P>0.05)$, although there seems to be a decreasing trend over time.

Although the majority of the poor and medium farmers (59 per cent) receive seeds from others in the community as compared to rich farmers (Table 10), all farmers in the community have equal access to the nodal and other farmers for seed and information. Farmers from every ethnic category, gender, and occupation have equal access to the seed sources and to the nodal farmers in the community. Household heads (decision makers) with nonagricultural occupations are less likely to receive seeds from the other farmers or from the nodal farmers as compared to full time farmers. The study also reveals that educated farmers who are also likely to 
be nodal farmers do not receive seeds from others in the community.

The majority of the poor farmers are receiving seeds from others in the community because they could not retain seeds due to lack of the storage, poor seed quality, and poor productivity. The rich farmers have better access to other sources such as research institutions and markets for seeds of new varieties. However, there was no discrimination in providing the seeds to the poor by the resource-rich and medium nodal farmers in the community. Similarly, the educated people who are also most of the nodal farmers usually do not receive seeds from others in the community and as they get seeds from other sources. Furthermore, younger household heads/decision makers are more likely to receive seeds and materials from the outside, as they are often interested in new varieties and are more willing to take risks in the community. This is because the older people either become less active in farming or they are the ones who usually keep their own seeds. This is also supported by the findings of Poudel and Johnsen [33]. They found that most often the older people provide seeds to the younger people creating the source-sink relationship. The lesson learned from the study is that nodal farmers usually bring new seeds into the community from the outside and do not receive seeds from farmers within their community.

6.3. Farmers' Network for on-Farm Conservation and Sustainable Use. The informal flow of seed materials meets the seed needs of the community members and maintains diversity on farm. Farmer Seed networks are keys to on-farm conservation of crop genetic resources [34,35]. Seed supply of traditional varieties of underutilized crops is almost entirely provided by informal/social seed systems. Strengthening the social seed system that promotes the role of farmers as conserver and innovator is essential for on-farm conservation and sustainable use of agricultural biodiversity. If the social seed system is open, dynamic, and decentralized [36], farmers can search for new genetic diversity, select specific traits useful to them, and manage crop population by seed selection practices. If farmers appreciate the cultivar, they will continue to grow it and exchange seeds with relatives and friends in their social networks. Access to sufficient seed, particularly of the farmer preferred varieties, is important in encouraging farmers to maintain diversity on farm. As the exchanging of seed materials in the community is one of the major means of seed flow, this can be further enhanced by improving the conditions that enable more farmers to exchange the materials. Strengthening the collective actions of communities in variety access, selection and seed production activities will ensure the flow of quality seeds in the community. This process will strengthen farmer's capacity to cope with climate change in traditional production systems. Furthermore, these networks are also actively engaged in the development of onfarm seed management systems that allow them to diversify their genetic resources, reduce costs, and strengthen control over their resource base [37].

The main weakness of social seed system is that access to new varieties from the formal systems, that is, breeding programmes or gene banks, is very limited due to poor connection with formal institution. The social seed networks can be strengthened by systematic interventions that improve access to extant and new diversity (e.g., seed fair, community seed bank, etc.), skills of trait identification, and selection and the maintenance of selected variety. With better exposure of farmers in breeding skills and knowledge, participatory plant breeding (PPB) can strengthen farmer seed systems (defined as the ways in which farmers produce, select, save, and acquire seeds [38]) to promote on-farm management and sustainable use of local crop diversity [39-41], that could be regarded as a custodian farmers [42].

It is argued that nodal farmers and social seed networks have little predictive value unless there is a certain degree of stability in a seed system. Results show that nodal farmers change from year to year and new nodal farmers appear within the network. Therefore, role of nodal farmers in deploying new diversity is positive in terms of agroecosystem resilience. However, poor stability of nodal farmers might cause difficulty in recognizing them and therefore to target nodal farmers as a "changed agent" might not be an efficient approach. Nevertheless, the stability of the network membership over time is fairly high (21-62\% with mean of $44 \%)$ suggesting that some network members remain the same individuals as others become the new nodal farmers. This might be useful for on-farm conservation of agricultural biodiversity as the system become open, dynamic and decentralized.

In this study, the nodal farmers are defined in narrow context of rice seed flow and it is important to understand underlying rationale of specific social connection with nodal farmers. If nodal farmers are defined as source of sustainable livelihood assets (i.e., knowledge, credit, seed, connection, etc.) in a broader sense, they could be more stable and probably have greater influence on the community. Study in a greater depth remains for future work.

\section{Conflict of Interests}

The authors declare that there is no conflict of interests regarding the publication of this paper.

\section{Acknowledgments}

The field research was supported by grants from the SDC, DGIS, and IDRC. The authors would also like to thank Toby Hodgkin, Devra Jarvis, Sriram Subedi, Sajal Sthapit, Paul Quek, Pitamber Shrestha, and two anonymous reviewers for their valuable inputs in the study. Diwakar Poudel also acknowledges the NFR no. 216571/E40.

\section{References}

[1] V. Krebs, An Introduction to Social Network Analysis, 2005, http://www.orgnet.com/sna.html.

[2] C. J. M. Almekinders, N. P. Louwaars, and G. H. de Bruijn, "Local seed systems and their importance for an improved seed supply in developing countries," Euphytica, vol. 78, no. 3, pp. 207-216, 1994. 
[3] R. Tripp, Seed Provision and Agricultural Development, Overseas Development Institute, London, UK, 2001.

[4] L. B. Badstue, M. R. Bellon, J. Berthaud et al., "Examining the role of collective action in an informal seed system: a case study from the Central Valleys of Oaxaca, Mexico," Human Ecology, vol. 34, no. 2, pp. 249-273, 2006.

[5] A. Subedi, P. Chaudhary, B. K. Baniya et al., "Who maintains crop genetic diversity and how: implication for on farm conservation and utilization?" Culture and Agriculture, vol. 25, no. 2, pp. 41-50, 2003.

[6] T. Hodgkin, R. B. Rana, J. Tuxill et al., "Seed systems and crop genetic diversity in agroecosystems," in Managing Biodiversity in Agricultural Ecosystems, D. I. Jarvis, C. Padoch, and H. D. Cooper, Eds., Bioversity International and Columbia University Press, SDC, IDRC, UNU and CBD, New York, NY, USA, 2007.

[7] D. Poudel, P. K. Shrestha, A. Basnet, B. Sthapit, and A. Subedi, "Stability of farmers' networks and nodal farmers in rice seed flow system: does it matter for on-farm conservation?" in OnFarm Management of Agricultural Biodiversity in Nepal: Lessons Learned: Proceeding of National Symposium, Kathmandu, Nepal, July 2006, B. R. Sthapit and D. Gauchan, Eds., 2007.

[8] A. Subedi, D. Singh, P. Shrestha, S. R. Subedi, and B. R. Sthapit, "Stability of farmers' networks and nodal farmers in terai and hill villages of Nepal: implications for agro-biodiversity management on-farm," in On Farm Conservation of Agricultural in Nepal, B. R. Sthapit, M. P. Upadhyay, P. K. Shrestha, and D. I. Jarvis, Eds., IPGRI, 2005.

[9] F. Abay, W. de Boef, and Å. Bjørnstad, "Network analysis of barley seed flows in Tigray, Ethiopia: supporting the design of strategies that contribute to on-farm management of plant genetic resources," Plant Genetic Resources: Characterisation and Utilisation, vol. 9, no. 4, pp. 495-505, 2011.

[10] L. A. Hoang, J.-C. Castella, and P. Novosad, "Social networks and information access: implications for agricultural extension in a rice farming community in northern Vietnam," Agriculture and Human Values, vol. 23, no. 4, pp. 513-527, 2006.

[11] M. Thomas, E. Demeulenaere, J. C. Dawson et al., "On-farm dynamic management of genetic diversity: the impact of seed diffusions and seed saving practices on a population-variety of bread wheat," Evolutionary Applications, vol. 5, no. 8, pp. 779795, 2012.

[12] S. Wasserman and K. Faust, Social Network Analysis: Methods and Applications, Cambridge University Press, Cambridge, UK, 1994.

[13] J. Scott, Social Network Analysis: A Handbook, Sage Publications, London, UK, 2004.

[14] L. C. Freeman, S. P. Borgatti, and D. R. White, "Centrality in valued graphs: a measure of betweenness based on network flow," Social Networks, vol. 13, no. 2, pp. 141-154, 1991.

[15] M. E. J. Newman, "A measure of betweenness centrality based on random walks," Working Paper, Department of Physics and Center for the Study of Complex Systems, University of Michigan, 2003.

[16] M. Newman and M. Girvan, "Finding and evaluating community structure in networks," Physical Review E, vol. 69, no. 2, Article ID 026113, 2004.

[17] J. Ford and D. R. Fulkerson, Flows in Networks, Princeton University Pres, Princeton, NJ, USA, 1962.

[18] R. B. Rana, C. Garforth, B. Sthapit, and D. Jarvis, "Influence of socio-economic and cultural factors in rice varietal diversity management on-farm in Nepal," Agriculture and Human Values, vol. 24, no. 4, pp. 461-472, 2007.
[19] R. S. Burt, "Models of network structure," Annual Review of Sociology, vol. 6, no. 1, pp. 79-141, 1980.

[20] E. M. Rogers and D. L. Kincaid, Communication Networks: Towards a New Paradigm for Research, The Free Press, New York, NY, USA, 1981.

[21] D. Knoke and J. H. Kuklinski, Network Analysis, Sage Publications, Beverly Hills, Calif, USA, 1982.

[22] R. B. Rana, P. Chaudhary, D. Gauchan et al., "In situ crop conservation: findings of agro-ecological, crop diversity and socioeconomic baseline survey of Kachorwa Eco-site Bara, Nepal," NP Working Paper No. 1/2000, 2000.

[23] R. B. Rana, D. K. Rijal, D. Gauchan et al., "In situ crop conservation: findings of agro-ecological, crop diversity and socioeconomic baseline survey of Begnas ecosite, Kaski, Nepal," NP Working Paper 2/2000, NARC/LI-BIRD/RPGRI, Rome, Italy, 2000.

[24] S. P. Borgatti, M. G. Everett, and L. C. Freeman, Ucinet for Windows: Software for Social Network Analysis, Analytic Technologies, Harvard, Mass, USA, 2002.

[25] S. P. Borgatti, NetDraw Network Visualization, Analytic Technologies, Harvard, Mass, USA, 2005.

[26] P. Shrestha, B. R. Sthapit, A. Subedi, D. Poudel, and B. K. Joshi, "On-farm management of agricultural biodiversity through community seed bank in Nepal," in Proceedings of the National Symposium on In-Situ Conservation of Agricultural Biodiversity On-Farm: Good Practices and Lessons Learned, Kathmandu, Nepal, July 2006.

[27] R. Vernooy, B. Sthapit, G. Galluzzi, and P. Shrestha, "The multiple functions and services of community seedbanks," Resources, vol. 3, no. 4, pp. 636-656, 2014.

[28] D. Louette, "Traditional management of seed and genetic diversity. What is landrace?" in On Farm Conservation of Crop Diversity, S. B. Brush, Ed., pp. 109-142, Lewis Publishers, Boca Raton, Fla, USA, 2000.

[29] T. Green, "Farmer-to-farmer seed exchange in the eastern hills of nepal: the case of 'Pokhareli Masio' rice," Tech. Rep. Working paper 05/87, Pakhribas Agricultural Centre, Dhankuta, Nepal, 1987.

[30] M. R. Bellon, "Conceptualizing interventions to support onfarm genetic resource conservation," World Development, vol. 32, no. 1, pp. 159-172, 2004.

[31] Z. Bishaw, P. C. Struik, and A. J. G. van Gastel, "Wheat and barley seed system in Syria: farmers, varietal perceptions, seed sources and seed management," International Journal of Plant Production, vol. 5, no. 4, pp. 323-348, 2011.

[32] N. Alvarez, E. Garine, C. Khasah, E. Dounias, M. H. McKey, and D. McKey, "Farmers'practices, meta-population dynamics, and conservation of agricultural biodiversity on farm: a case study of sorghum among Duppa in sub-sahelian Cameroon," Biological Conservation, vol. 121, pp. 533-543, 2005.

[33] D. Poudel and F. H. Johnsen, "Valuation of crop genetic resources in Kaski, Nepal: farmers' willingness to pay for rice landraces conservation," Journal of Environmental Management, vol. 90, no. 1, pp. 483-491, 2009.

[34] M. Pautasso, G. Aistara, A. Barnaud et al., "Seed exchange networks for agrobiodiversity conservation. A review," Agronomy for Sustainable Development, vol. 33, no. 1, pp. 151-175, 2013.

[35] P. M. Stromberg, U. Pascual, and M. R. Bellon, "Seed systems and farmers' seed choices: the case of maize in the Peruvian Amazon," Human Ecology, vol. 38, no. 4, pp. 539-553, 2010. 
[36] M. R. Bellon, "Do we need crop landraces for the future? Realizing the global option value of in situ conservation," in Agrobiodiversity and Economic Development, A. Kontoleon, U. Pascual, and M. Smale, Eds., Routledge, New York, NY, USA, 2008.

[37] E. Da Vía, "Seed diversity, farmers'rights, and the politics of repeasantization," International Journal of Sociology of Agriculture and Food, vol. 19, no. 2, pp. 229-242, 2012.

[38] K. Vom Brocke, T. Presterl, A. Christinck, E. R. Weltzien, and H. H. Geiger, "Farmers' seed management practices open up new base populations for pearl millet breeding in a semi-arid zone of India," Plant Breeding, vol. 121, no. 1, pp. 36-42, 2002.

[39] M. Halewood, P. Deupmann, B. Sthapit, R. Vernooy, and S. Ceccarelli, Participatory Plant Breeding to Promote Farmers'Rights, Bioversity International, Rome, Italy, 2007.

[40] L. Sperling, J. A. Ashby, M. E. Smith, E. Weltzien, and S. Mcguire, "A framework for analyzing participatory plant breeding approaches and results," Euphytica, vol. 122, no. 3, pp. 463475, 2001.

[41] C. J. M. Almekinders, G. Thiele, and D. L. Danial, "Can cultivars from participatory plant breeding improve seed provision to small-scale farmers?" Euphytica, vol. 153, no. 3, pp. 363-372, 2007.

[42] B. Sthapit, H. Lamers, and R. Rao, "Custodian farmers if agricultural biodiversity: selected profiles form south and south east Asia," in Proceedings of the workshop on Custodian Farmers of Agricultural Biodiversity, Bioversity International, New Delhi, India, February 2013. 

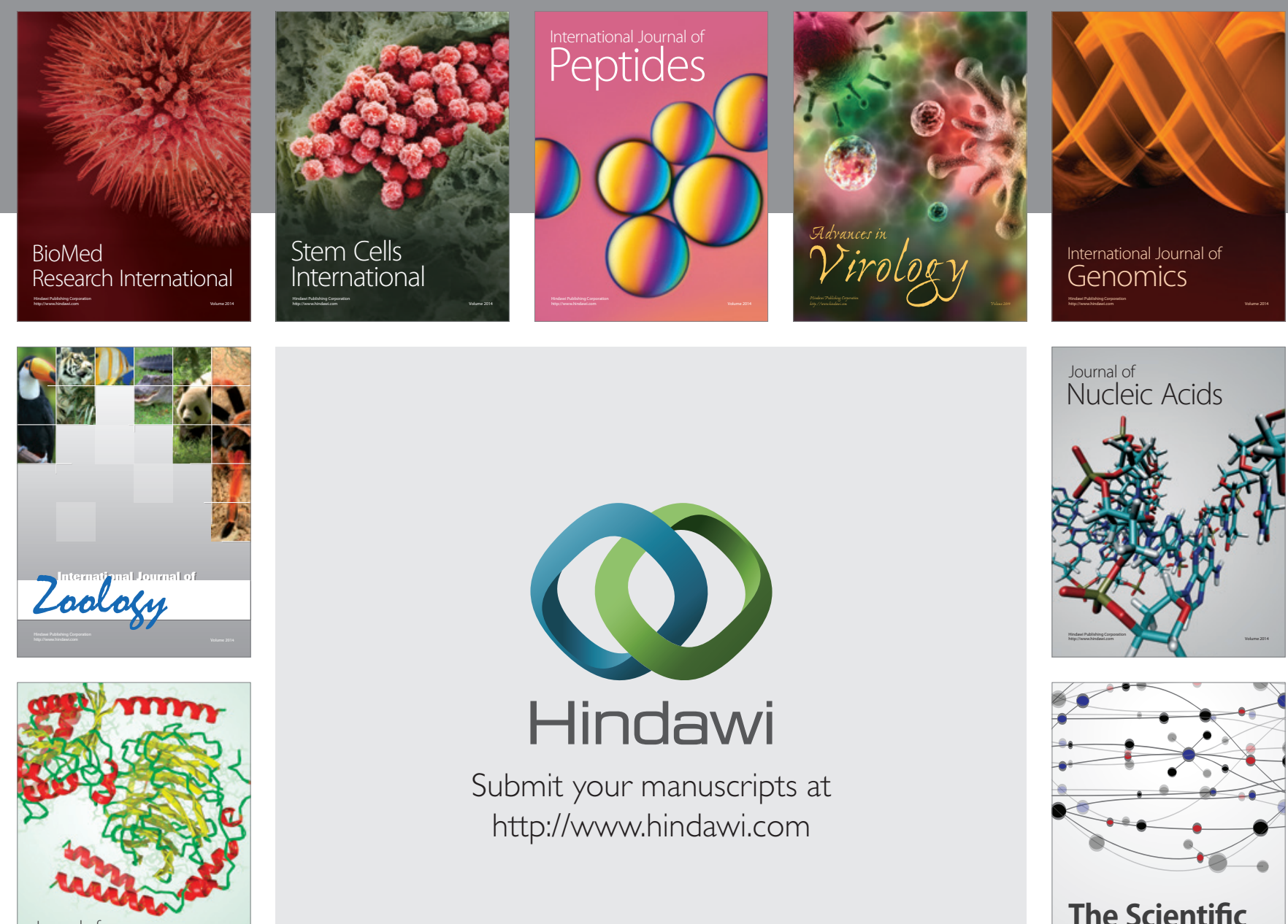

Submit your manuscripts at

http://www.hindawi.com

Journal of
Signal Transduction
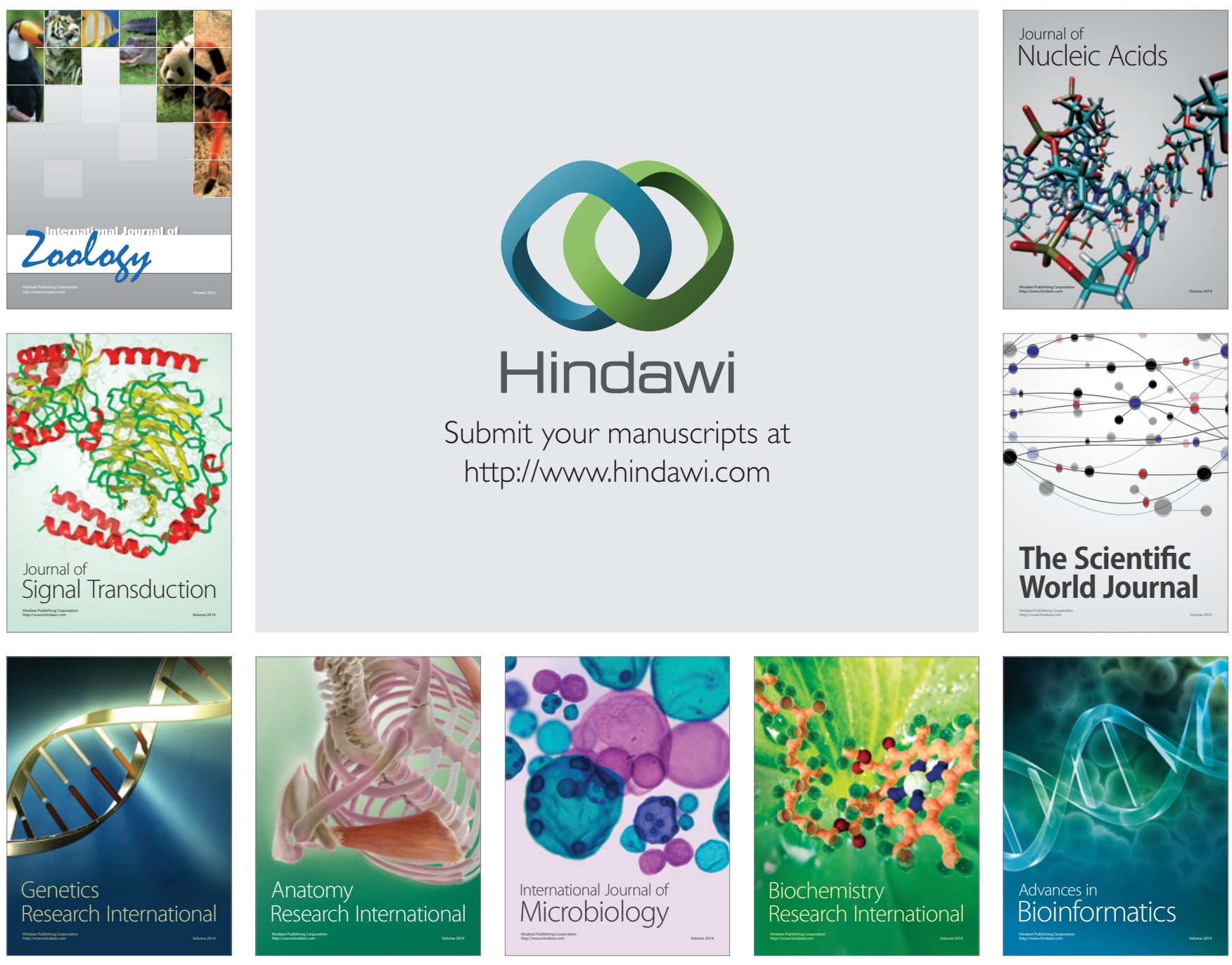

The Scientific World Journal
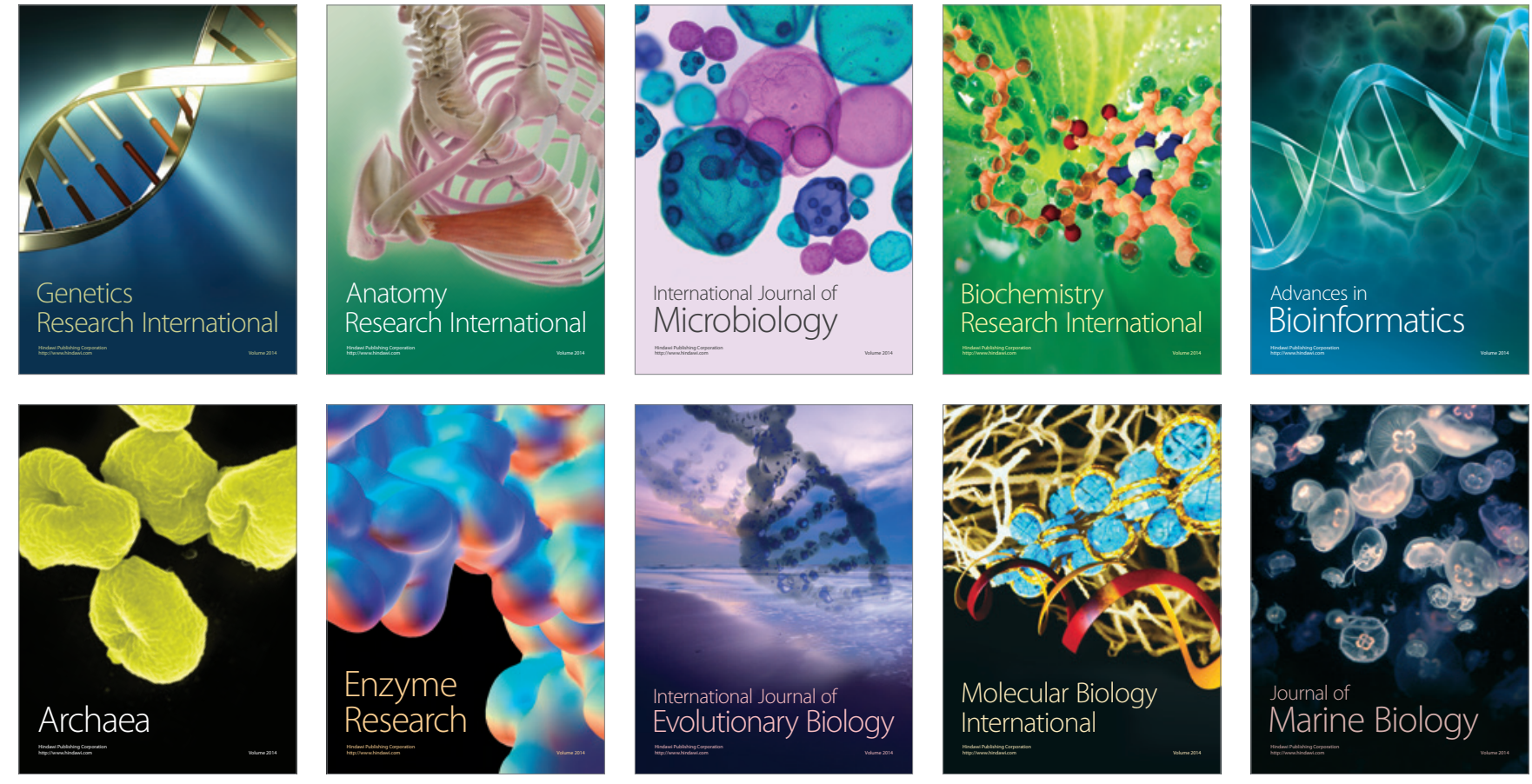